\title{
Efektivitas Proses Rekrutmen Pegawai Negeri Sipil di Sekretariat Pendidikan Wilayah Administratif Khusus Oekusi Ambeno - Timor Leste
}

\section{The Effectiveness of The Recruitment of Civil Servants in The Education Secretariat of The Special Administrative Area of Oecussion Ambeno - Timor Leste}

\author{
Hermenegildo Sipa, Ida Hayu Dwimawanti, Augustin Rina Herawati \& Teuku \\ Afrizal* \\ Program Studi Administrasi Publik, Fakultas Ilmu Sosial dan Ilmu Politik, \\ Universitas Diponegoro, Indonesia \\ Diterima: 15 Juni 2021; Direview: 02 Agustus 2021; Diestujui: 19 Agustus 2021
}

*Coresponding Email: teukurian@lecturer.undip.ac.id

\begin{abstract}
Abstrak
Penelitian ini fokus pada proses rekrutmen pegawai negeri sipil, merujuk pada efektivitas yang harus dilaksanakan dengan benar, memberikan hasil yang bermanfaat dan mencapai tujuan. Sekretariat Pendidikan, Pemerintah Daerah Administratif Khusus Oekusi, Timor Leste melakukan rekrutmen untuk mencari, menemukan pelamar dan menghasilkan pegawai negeri sipil yang memiliki kualitas, kemampuan, kompetensi dan pengetahuan sesuai kebutuhan. Dalam meneliti efektivitas proses rekrutmen tersebut, digunakan jenis penelitian kualitatif yang didefinisikan secara beragam sesuai dengan sudut pandang yang dipakai oleh para ahli. Ada tiga penemuan yang ditemukan dalam penelitian ini yakni pelanggaran syarat administratif, proses rekrutmen tidak efektif dan tidak memenuhi standar rekrutmen, dan adanya kompromi dan intervensi politik. Penutup dari hasil penelitian tersebut, artikel ini selain memberikan sumbangan informatif tetapi juga sebagai bahan referensi dalam melakukan atau perbaikan proses rekrutmen yang efektif diwaktu yang akan datang.
\end{abstract}

Kata Kunci: Efektivitas; Proses Rekrutmen.

\begin{abstract}
This research focuses on the process of recruitment of civil servants, referring to the effectiveness that must be carried out properly, provide useful results and achieve goals. Secretariat of Education, Special Administrative Region of Oecusi, Timor Leste conducts recruitment to find, find applicants and produce civil servants who have the quality, ability, competence and knowledge as needed. In examining the effectiveness of the recruitment process, qualitative research types are used which are defined in various ways according to the viewpoints used by experts. There are three findings found in this study, namely a) violations of administrative requirements, $b$ ) the recruitment process is ineffective and does not meet recruitment standards, and c) there is compromise and political intervention. Closing the results of the research, this article in addition to providing informative contributions but also as a reference material in conducting or improving an effective recruitment process in the future.
\end{abstract}

Keywords: Effectiveness; Recruitment Process.

How to Cite: Sipa, H., Dwimawanti, I.H., Herawati, A.R., \& Afrizal, T. (2021). Efektivitas Proses Rekrutmen Pegawai Negeri Sipil di Sekretariat Pendidikan Wilayah Administratif Khusus Oekusi Ambeno - Timor Leste. Journal of Education, Humaniora and Social Sciences (JEHSS). 4 (2): 1081-1089. 


\section{PENDAHULUAN}

Pada tahun 2014 Pemerintah Timor Leste Membentuk Daerah Administratif Khusus Oekusi Ambeno yang tertuang dalam undang-undang nomor 3 tahun 2014, tertanggal 8 Juni. Sesuai dengan perintah konstitusi tersebut di atas, maka wilayah Oekusi Ambeno diangkat menjadi daerah khusus yang diberkahi dengan otonomi administratif, keuangan dan patrimonial, badan hukum. Dalam menjalankan pemerintah daerah memerlukan sumber daya manusia yang berkwalitas. Perekrutan pegawai negeri sipil menjadi tanggungjawab pemerintah daerah untuk memastikan kekuatan sumber daya manusia dalam membangun sebuah pemerintah yang kokoh dan mampu menyelenggarakan fungsi administratif dengan baik sesuai dengan amanat undangundang.

Dewasa ini terjadi penataan kembali akibat arus reformasi yang mengagendakan upaya pembenahan jajaran birokrasi pemerintah demi menjamin kualitas organisasi pemerintah. Mengingat kebijakan Kementerian Pendidikan Timor Leste melalui Sekretariat Pendidikan, Daerah Administratif Khusus Oekusi lebih berhati-hati dalam proses rekrutmen, supaya mendapatkan pegawai yang handal, sehingga meskipun jumlah pegawai tidak terlalu banyak, namun tugas dan fungsi dapat ditunaikan dengan lancar. Hal tersebut dapat terpenuhi apabila proses rekrutmen dapat dilakukan dengan baik dan bersih dari korupsi, kolusi dan nepotisme.

Pada tahun 2020 Sekretariat Pendidikan Daerah Administratif Khusus Oekusi merekrut calon pegawai negeri sipil sebagai inspektur untuk mengawas sekolah-sekolah baik sekolah negeri maupun swasta. Inspektur sekolah yang direkrut sebagai pegawai negeri sipil berkerja sesuai dengan visi dan misi yang dibuat Kementerian Pendidikan Timor Leste. Ada 5 kompetensi yang harus dimiliki seorang inspektur sekolah adalah professional, bahasa, teknik, supervisor dan peneliti. Tugas dari inspektur sekolah adalah mempromosikan dan atau menjaga kualitas dan tanggungjawab sekolah antara lain melakukan control administrasi, sumber daya, keuangan sekolah, melakukan penilaian, pengamatan proses belajar mengajar di sekolah, menjaga keutuhan bangunan dan fasilitas sekolah, menjaga relasi atau menjadi mediator antara orangtua siswa dan guru-guru di sekolah, dan melakukan perencanaan dan pengawasan perencanaan sekolah (Manual Inspektur Sekolah, Kementerian Pendidikan Timor Leste, 2019: 1-10).

Salah satu cara dalam mencari sumber daya manusia yang berkualitas yaitu melalui rekrutmen (Suhendra, 2017). Rekrutmen adalah serangkaian aktivitas dalam sebuah organisasi yang memerlukan tenaga kerja atau sumber daya manusia, membuka lowongan sampai pada mendapat calon yang diinginkan. Rekrutmen merupakan sebuah proses dimana organisasi pemerintah ataupun swasta mencari, menemukan dan menarik para pelamar untuk diberikan suatu pekerjaan yang dibutuhkan organisasi. Didalam proses perekrekrutan mencari memikat para pelamar dengan motivasi yang baik, kemampuan, keahlian, dan pengetahuan untuk menutupi kekurangan yang dalam sebuah organisasi yang telah diidentifikasi. Metode perekrutan biasanya digunakan adalah: pencarian sumber dari dalam/internal organisasi dan pencarian sumber dari luar/eksternal organisasi. Menurut SP. Siagian diadakan rekrutmen adalah untuk mendapatkan persediaan sebanyak mungkin calon-calon pelamar sehingga organisasi akan mempunyai kesempatan yang lebih besar untuk melakukan pilihan terhadap calon pegawai yang dianggap memenuhi standar kualifikasi organisasi. Adapun prosedur rekrutmen pegawai negeri sipil yaitu perencanaan kebutuhan pegawai, analisis jabatan, penyusunan formasi, dan pengadaan. Supaya dapat melakukan prosedur rekrutmen secara efektif, harus tersedia informasi akurat, kerjasama baik dari pegawai, pelamar dan berkelanjutan mengenai jumlah dan kualifikasi individu yang diperlukan untuk melaksanakan berbagai tugas pokok dan fungsi dalam instansi.

Proses rekrutmen dikatakan efektif bila kegiatan tersebut dilaksanakan dengan benar dan memberikan hasil yang bermanfaat. Mengukur efektivitas suatu program kegiatan bukanlah suatu hal yang sangat sederhana, karena efektivitas dapat dikaji dari berbagai sudut pandang dan tergantung pada siapa yang menilai serta menginterpretasikannya. Tingkat efektivitas juga dapat diukur dengan membandingkan antara rencana yang telah ditentukan dengan hasil nyata yang telah diwujudkan.

Efektivitas perekrutan dapat dicapai dengan beberapa hal, yaitu: Melakukan perencanaan perekrutan dimulai dengan pembuatan perencanaan sumber daya manusia yang diselaraskan 10.8.2 http://mahesainstitute.web.id/ojs2/index.php/jehss v. mahesainstitut@gmail.com

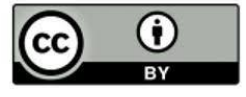


dengan strategi organisasi di masa mendatang; Perencanaan pelaksanaan perekrutan menggunakan standar sistem manajemen sumber daya manusia yang telah dimiliki berupa kompetensi jabatan, spesifikasi jabatan dan deskripsi jabatan; Menggunakan metode perekrutan yang menggabungkan atau kombinasi dari beberapa metode sekaligus agar mendapatkan lamaran yang lebih banyak dan lebih memenuhi kualifikasi; Melakukan evaluasi secara terus-menerus untuk mengukur efektifitas metode perekrutan yang digunakan sesuai dengan kualifikasi jabatan yang dibutuhkan. Dengan demikian efektivitas terkait dengan pencapaian sasaran atau tujuan.

Realitas rekrutmen yang dilakukan Pemerintah Daerah Administratif Khusus Oekusi melalui Sekretariat Pendidikan Oekusi tidak sesuai dengan standar administratif. Ada dua ketentuan persyaratan utama yang harus dipenuhi calon inspektur yaitu kriteria perekrutan seorang calon dan persyaratan dokumen. Ada dua indikasi pelanggaran yakni pertama, pada kriteria perekrutan antara lain ada pelamar belum memiliki pengalaman kerja sebagai kepala sekolah minimal dua tahun dan belum memiliki pengalaman kerja di institusi pemerintah manapun. Kedua, tidak memenuhi persyaratan dokumen antara lain tidak ada surat rekomendasi dari sebuah institusi atau salah satu sekolah dan tidak ada sertifikasi mengenai profesi kepala sekolah. Menurut informasi dikatakan bahwa ada pelamar yang memenuhi ketentuan persyaratan namun tidak lolos dalam seleksi berkas dan tahap akhir interview. Dan yang dinyatakan lolos dalam perekrutan inspektur di Sekretariat Pendidikan Oekusi - RAEOA adalah mereka yang tidak memiliki keahlian, pengetahuan, kemampuan dan kualifikasi.

Berdasarkan Manual Inspektur Sekolah, Kementerian Pendidikan Timor Leste tahun 2019 diharuskan seorang inspektur (Pegawai Negeri Sipil) harus memenuhi persyaratan agar menjamin kualitas dan tanggungjawab sekolah. Tetapi karena adanya kelemahan dalam proses perekrutan maka kegiatan atau hasil kerja dipertanyakan dan dianggap tidak maksimal. Tidak ada jaminan kualitas dan tanggungjawab dari para calon inspektur. Meskipun sudah ada Job description dalam Manual Inspektur Sekolah, Kementerian Pendidikan Timor Leste tetapi tidak ada kapasitas untuk mampu melaksanakannya.

Etzioni (1982) yang mendefinisikan efektifitas organisasi yaitu "Efektivitas Organisasi merupakan sebagai tingkat sejauh mana organisasi berhasil dalam mencapai tujuannya". Steers (2005) mengemukakan bahwa efektivitas adalah jangkauan usaha suatu program sebagai suatu sistem dengan sumber daya dan sarana tertentu untuk memenuhi tujuan dan sasarannya tanpa melumpuhkan cara dan sumber daya itu serta tanpa memberi tekanan yang tidak wajar terhadap pelaksanaannya. Chester Barnard dalam Gibson dkk, (2002) mendefinisikan efektivitas sebagai tingkat percapaian tujuan dan sasaran yang telah ditentukan sebelumnya. Menurut Edi (2007: 125) dalam mengukur efektivitas suatu kegiatan atau program perlu diperhatikan beberapa indikator, yaitu: Pemahaman program; Tepat sasaran; Tepat waktu; Tercapainya tujuan; Perubahan nyata.

Menurut Rosento (2018) pandangan tentang Efektivitas merupakan pencapaian suatu kegiatan sesuai dengan rencana. Suatu pekerjaan dikatakan efektif apabila dapat mencapai tujuan sebagaimana yang direncanakan dengan menggunakan segala sumber daya yang telah direncanakan pula. Suatu pekerjaan yang dilakukan oleh seseorang, akan menunjang pencapaian tujuan secara kelompok. Hal ini dikarenakan setiap organisasi terbagi menjadi beberapa bagian atau kelompok.

Menurut Rivai (2004) dalam Elga Septhinna dkk (2009), rekrutmen adalah serangkaian kegiatan yang dimulai ketika sebuah perusahaan atau organisasi memerlukan tenaga kerja dan membuka lowongan sampai mendapatkan calon karyawan yang diinginkan. Menurut Wasistiono dalam Agus (2018) rekrutmen pegawai dilakukan karena adanya kebutuhan organisasi akan tenaga kerja/karyawan atau untuk mengisi jabatan-jabatan yang masih kosong. Schuler dan Jackson (1997 : 227) mengartikan bahwa rekrutmen adalah meliputi upaya pencarian sejumlah calon karyawan yang memenuhi syarat dalam jumlah tertentu, sehingga dari mereka perusahaan atau organisasi dapat menyeleksi orang-orang yang paling tepat untuk mengisi lowongan pekerjaan yang ada. Sedangkan Nawawi (2005) mendefinisikan rekrutmen merupakan suatu 
proses mendapatkan sejumlah calon tenaga kerja yang kualified untuk jabatan/pekerjaan utama (produk lini dan penunjangnya) di lingkungan suatu organisasi.

Dilihat dari berbagai penjelasan di atas dapat dikemukakan ada istilah pokok dalam rekrutmen ini bahwa sebuah proses rekrutmen dimulai dengan pencarian calon dan terakhir sampai lamaran mereka diterima. Menurut Rachmawanto (2013) metode rekrutmen merupakan kegiatan tentang bagaimana menarik calon pegawai untuk melamar. Dan setiap rekrutmen pegawai menurut Khotimah (2013) harus diumumkan seluas-luasnya melalui media masa atau media lainnya.

Menurut Herawati (2015) proses rekuitmen bisasanya diawali dari proses seleksi. Gatewood dan Field dalam Herawati (2015) menyatakan bahwa seleksi adalah proses pengumpulan dan evaluasi informasi tentang individu yang memperoleh tawaran pekerjaaan. Sementara Siagian (1994) menyatakan bahwa seleksi adalah berbagai langkah spesifik yang diambil untuk memutuskan pelamar mana yang akan diterima dan pelamar mana yang akan ditolak. Menurut Nunik proses seleksi adalah langkah-langkah yang harus dilalui oleh para pelamar sampai akhirnya memperoleh keputusan ia diterima atau ditolak sebagai karyawan baru. Sedangkan menurut Simamora (2004) tujuan seleksi yaitu adalah untuk mendapatkan dan mencocokkan secara benar dengan pekerjaan untuk memenuhi kualifikasi sebagaimana tercantum dalam job description.

Menurut Herawati (2015) untuk memperoleh dan mendapatkan peluang jabatan tersebut maka perlu dilakukan melalui seleksi yang obyektif untuk dapat diperoleh pegawai yang berkualitas sesuai dengan kebutuhan. Proses rekuitmen sebaiknya juga sesuai prosedur dan dilakukan secara transparan terbebas dari KKN sehingga bisa diperoleh PNS yang berdedikasi. Sedangkan menurut Febby Triandini (2017) transparansi proses penerimaan CPNS merupakan salah satu upaya yang dapat ditempuh dalam rangka memulihkan kepercayaan masyarakat. Transparansi dalam pola rekruitmen CPNS bermanfaat untuk memberikan informasi akurat, cepat, dan lengkap kepada masyarakat.

Tujuan rekrutmen menurut Sulistiyani (2004) adalah kegiatan menarik pegawai baru maupun pegawai lama untuk menduduki posisi ataupun jabatan yang lowong. Disamping itu tujuan umum rekrutmen adalah menyediakan karyawan yang memenuhi syatat-syarat bagi segala kebutuhan organisasi. Sedangkan menurut Gomes (2003 : 105) dalam Ajib Rakhmawanto (2013 : 4), rekrutmen merupakan proses mencari, menemukan, dan menarik para pelamar untuk dipekerjakan dalam dan oleh suatu organisasi. Menurut Sulistiyani (2002) pada prinsipnya rekrutmen merupakan proses mencari, menemukan dan menarik para pelamar yang sesuai untuk menjadi pegawai dalam dan oleh suatu instansi. Selanjutnya rekrutmen juga dapat didefinisikan sebagai serangkaian aktivitas mencari memikat pelamar kerja dengan motivasi, kemampuan, keahlian, dan pengetahuan yang diperlukan guna menutupi kekurangan yang diidentifikasi dalam perencanaan kepegawaian.

Proses rekrutmen meliputi beberapa poin penting, menurut (Simamora 2006): Penyusunan strategi untuk merekrut Di dalam penyusunan strategi ini, departemen sumber daya manusia bertanggung jawab didalam menentukan kualifikasi-kualifikasi pekerjaan, bagaimana karyawan akan direkrut, dimana, dan kapan. Penyisihan pelamar-pelamar yang tidak cocok/penyaringan Setelah lamaran-lamaran diterima, haruslah disaring guna menyisihkan individu yang tidak memenuhi syarat berdasarkan kualifikasi-kualifikasi pekerjaan. Di dalam proses ini memerlukan perhatian besar khususnya untuk membendung diskualifikasi karena alasan yang tidak tepat, sehingga di dalam proses ini dibutuhkan kecermatan dari pihak penyaring.

Pembuatan kumpulan pelamar kelompok pelamar (applicant pool) terdiri atas individuindividu yang telah sesuai dengan kriteria yang telah ditetapkan oleh perekrut dan merupakan kandidat yang layak untuk posisi yang dibutuhkan.

Menurut Simamora (2004) menyatakan bahwa proses rekrutmen pada dasarnya menerapkan beberapa hal: Pengindentifikasian kebutuhan untuk melakukan pengadaan; Membuat deskripsi, spesifikasi, dan standar kinerja yang rinci; Menentukan sumber-sumber kandidat; Menentukan kriteria-kriteria rekrutmen; Menyeleksi sumber-sumber rekrutmen; 
Menyusun dan menyeleksi dan menjadwalkan program rekrutmen; Memberitahukan hasil kepada para pelamar; dan Menunjuk kandidat yang lolos seleksi.

Sedangkan Peraturan Pemerintah (nomor 98 tahun 2000 pasal 2 ayat 1) dikatakan proses rekrutmen mengacu pada tata cara pengadaan pegawai negeri sipil ada tahapan proses rekrutmen pegawai negeri sipil sebagai berikut: perencanaan kebutuhan pegawai, pengumuman, pelamaran, penyaringan/seleksi, pengangkatan calon pegawai negeri sipil, pengangkatan menjadi pegawai negeri sipil.

Dari uraian di atas maka penulis tertarik untuk mengadakan penelitian tentang rekrutmen Pegawai Negeri Sipil di Sekretariat Pendidikan Oekusi, RAEOA - Timor Leste dan menuangkannya dalam sebuah tulisan yang berjudul "Efektivitas Proses Rekrutmen Pegawai Negeri Sipil Di Sekretariat Pendidikan Wilayah Administratif Khusus Oekusi Ambeno".

\section{METODE PENELITIAN}

Jenis penelitian ini menggunakan metode penelitian kualitatif bersifat deskriptif. Dengan melakukan penelitian secara deskriptif dapat memberikan gambaran jelas tentang Efektivitas Proses Rekrutmen Pegawai Negeri Sipil Di Sekretariat Pendidikan Wilayah Administratif Khusus Oekusi Ambeno. Penelitian ini terbatas pada usaha mengungkapkan suatu masalah atau keadaan atau peristiwa sebagaimana adanya sehingga bersifat untuk mengungkapkan fakta. Jadi dalam penelitian deskriptif ini penulis melakukan pengukuran secara cermat terhadap suatu fenomena yang terjadi. Data Primer diperoleh dengan melakukan penelitian langsung terhadap objek penelitian dengan menggunakan teknik pengumpulan data observasi, interview atau wawancara. Sedangkan data sekunder ditemukan melalui studi pustaka dalam mengumpulkan data melalui dokumen, buku dan peraturan yang berhubungan langsung dengan obyek penelitian. Subyek dari penelitian ini adalah orang sebagai informan yang berhubungan langsung dan memiliki pengetahuan mengenai informasi-informasi pokok untuk memberikan informasi selama proses penelitian ini berlangsung. Penelitian ini menggunakan teknik triangulasi yang digunakan untuk menganalisis data.

Dari paparan di atas dan berdasarkan masalah yang diteliti serta tujuan penelitian maka yang menjadi fokus dalam penelitian ini adalah Efektivitas Proses Rekrutmen Pegawai Negeri Sipil Di Sekretariat Pendidikan Wilayah Administratif Khusus Oekusi Ambeno: Perencanaan kebutuhan pegawai; Pengumuman; Pelamaran; Penyaringan/seleksi; Pengangkatan calon pegawai negeri sipil; Pengangkatan menjadi pegawai negeri sipil.

\section{HASIL DAN PEMBAHASAN}

\section{Proses Perencanaan Kebutuhan Pegawai}

Dari hasil wawancara penulis dengan staff Sekretariat Pendidikan Wilayah Administratif Khusus Oekusi Ambeno bahwa sebelum pelaksanaan proses rekrutmen calon pegawai negeri sipil sebagai inspektur/pengawas sekolah, Pengurus atau Staff sumber daya manusia di Sekretariat Pendidikan telah melakukan perencanaan terlebih dahulu seperti perencanaan anggaran yang diperlukan, perencanaan jumlah formasi pegawai yang dibutuhkan dengan cara menganalisis kebutuhan pegawai untuk mendapatkan jumlah formasi yang tepat sasaran sesuai kebutuhan dari instansi tersebut, pembentukan panitia seleksi calon pegawai negeri sipil, perencanaan jadwal kegiatan pelaksanaan calon inspektur serta perencanaan kebutuhan sarana dan prasarana yang akan gunakan, semuanya itu sudah direncanakan. Selain itu juga, untuk mengadakan pengadaan calon pegawai negeri sipil (inspektur/pengawas sekolah) tahun 2020.

Perencanaan kebutuhan pegawai inspektur/pengawas sekolah terlebih dahulu dilakukan analisis kebutuhan pegawai inspektur yang kekurangan tenaga kerja kemudian diproses dan menghasilkan yang akan diajukan. Formasi tersebut kemudian disetujui oleh Presidente Autoridade Região Administrativa Especial Oecusse Ambeno (RAEOA), setelah persetujuan itu pihak Sekretariat Pendidikan Wilayah Administratif Khusus Oekusi Ambeno akan mengajukan formasi itu untuk diproses. Jumlah yang dibutuhkan oleh pihak Sekretariat Pendidikan Wilayah Administratif Khusus Oekusi Ambeno adalah 5 orang calon pegawai negeri sipil atau calon inspektur (pengawas 
sekolah). Maka hasil itu dikirim kembali untuk diumumkan bahwa akan ada penerimaan calon pegawai negeri sipil atau calon pengawas sekolah tahun Anggaran 2020.

Namun dalam perencanaan tersebut, menurut salah satu pegawai di sekretariat pendidikan bahwa tidak ada perencanaan mengenai apakah metode atau sumber rekrutmen ini dari sumber internal atau eksternal. Dalam proses perencanaan tidak termasuk sumber rekrutmen sehingga menimbulkan kecurigaan didalam instansi Sekretariat Pendidikan. Berdasarkan penelitian dan wawancara secara langsung, penulis dapat menyimpulkan bahwa rekrutmen calon pengawas sekolah dilakukan kurang efektif meskipun secara umum sudah mengikuti proses perencanaan kebutuhan pegawai.

\section{Pengumuman}

Dari hasil wawancara penulis dengan beberapa informan dapat disimpulkan bahwa dalam pengumuman pihak Sekretariat Pendidikan Wilayah Administratif Khusus Oekusi Ambeno telah mengumumkan seluas-luasnya bahwa akan ada alokasi formasi calon pegawai negeri sipil (inspektur/pengawas sekolah) yang akan dibuka, hal ini dilakukan agar tidak adanya kecurigaan atau kecurangan terhadap pihak-pihak tertentu dalam penerimaan calon pegawai negeri sipil di kota Oekusi Ambeno.

Dalam proses penerimaan formasi yang diberikan, diumumkan kepada masyarakat publik di kota Oekusi Ambeno. Pengumuman merupakan langkah penting dalam proses pengadaan, pengumuman dibuat dengan jelas, lengkap dan terbuka dengan menggunakan bahasa yang jelas dan dapat dipahami oleh pelamar baik itu formasi yang akan diisi, kualifikasi pendidikan yang dibutuhkan, syarat yang harus di penuhi pelamar dan lain-lain yang dianggap perlu. Pengumuman yang diadakan oleh pihak Sekretariat Pendidikan Wilayah Administratif Khusus Oekusi Ambeno telah dilakukan dengan media-media yang mudah dipahami, seperti alat komunikasi, media elektronik, media cetak, maupun pemasangan papan pengumuman yang ditempel di lingkungan sekretariat pendidikan kota Oekusi Ambeno. Pengumuman yang dilakukan pihak sekretariat pendidikan kota Oekusi Ambeno berlangsung selama 14 hari, mulai dari tanggal 30 Oktober 2020 sampai 13 Novermber 2020.

\section{Pelamaran}

Dari hasil obervasi penulis pelamar yang akan melamar terlebih dahulu harus melihat dan membaca kriteria dan persyaratan dokumen.

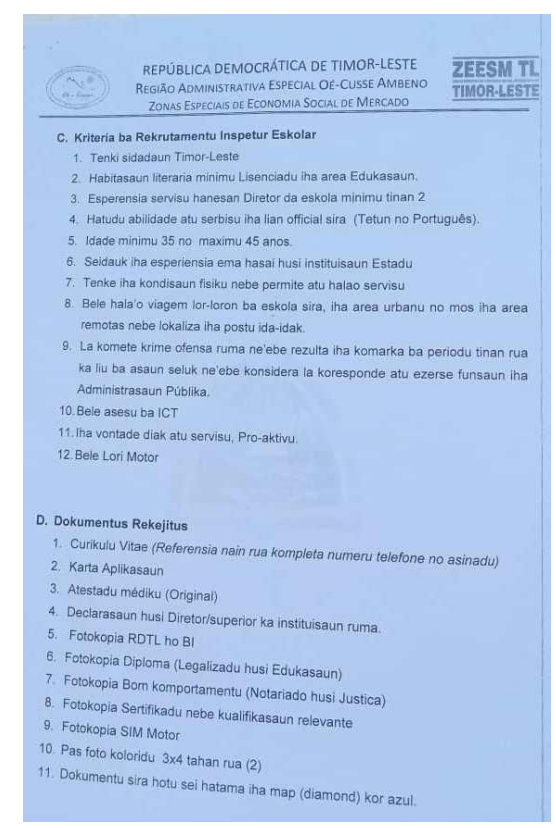

Gambar 1

Sumber: Sekretariat Pendidikan Pemerintah Daerah Administratif Khusus Oekusi Ambeno

1086 http://mahesainstitute.web.id/ojs2/index.php/jehss mahesainstitut@gmail.com 
Ada dua persyaratan pada Gambar 1 adalah sebagai berikut pertama, kriteria rekrutmen calon inspektur sekolah antara lain warga Negara Timor Leste, minimal sarjana pendidikan, pengalaman kerja sebagai kepala sekolah minimal 2 tahun, kemampuan bahasa Tetum dan Portugis, umur minimal 35 tahun dan maksimal 45 tahun, belum ada pengalam pemecatan pada institusi tertentu, riwayat kesehatan yang baik, bisa melakukan perjalanan ke pelosok, tidak ada tindakan kriminal sebelumnya, bisa akses internet dan computer, ada kemauan berkerja dan proaktif, dan bisa mengendarai kendaraan motor. Yang kedua adalah persyaratan dokumen antara lain: Curruculum Vitae, Surat Lamaran, Surat Kesehatan Original, Surat pernyataan dari salah satu atasan atau institusi, Foto Kopi Surat RDTL dan Kartu Identitas, Foto Kopi Diploma yang dilegaisir, Surat keterangan kelakuan baik, Sertifikat kualifikafikasi, Foto Kopi SIM, PasFoto 3x4 2 lembar, dan semua dokumen dimasukan dalam stopmap warna biru.

Setelah pengumuman berlangsung maka diberikan kesempatan kepada pelamar untuk mengajukan surat lamaran kepada pihak sekretariat pendidikan kota Oekusi Ambeno selama batas waktu yang telah ditentukan, dilakukan pada jam kerja, mulai jam 08:30-17:30 WTLS. Tidak ada pendaftaran online. Semua pelamar diharuskan untuk melakukan pendaftaran di kantor sekretariat pendidikan kota Oekusi Ambeno. Setelah pelamar mendaftar maka setiap pelamar harus mengajukan surat lamaran dengan melengkapi dua persyaratan yang disebutkan diatas.

\section{Penyaringan/Seleksi}

Dari hasil observasi penulis, penyaringan pegawai negeri sipil sebagai inspektur/pengawas sekolah di Kantor Sekretariat Pendidikan kota Oekusi Ambeno tidak berdasarkan ketentuan persyaratan yang telah ditetapkan. Yang diseleksi adalah mereka yang tidak memiliki pengalaman kerja sebagai Kepala Sekolah dan membuat surat pernyataan palsu dari salah satu sekolah. Menurut seorang informan dikatakan bahwa ada intervensi politik dan kelompok tertentu dalam melakukan penyaringan atau seleksi. Sehingga tidak memenuhi target yang ditentukan. Yang menurut perencanaan kebutuhan pegawai dibutuhkan 5 orang tetapi pada hasil seleksi akhir hanya mendapatkan 3 orang saja.

Seleksi penerimaan calon pegawai negeri sipil sebagai inspektur/pengawas sekolah di Kantor Sekretariat Pendidikan kota Oekusi Ambeno terbagi dalam 3 tahapan yakni seleksi berkas, tes tertulis dan tes wawancara. Dari hasil wawancara penulis dengan salah satu pelamar dikatakan ada 12 pelamar yang berhasil lolos tidak memenuhi seleksi berkas yaitu tidak ada sertifikat kualifikasi. Jadi yang mengikuti test tertulis sebanyak 12 orang dan sebanyak 8 orang yang lolos dan mengikuti tes wawancara. Dan pada akhirnya yang dinyatakan lolos sebagai inspektur/pengawas sekolah sebanyak 3 orang. 


\section{Gambar 2}

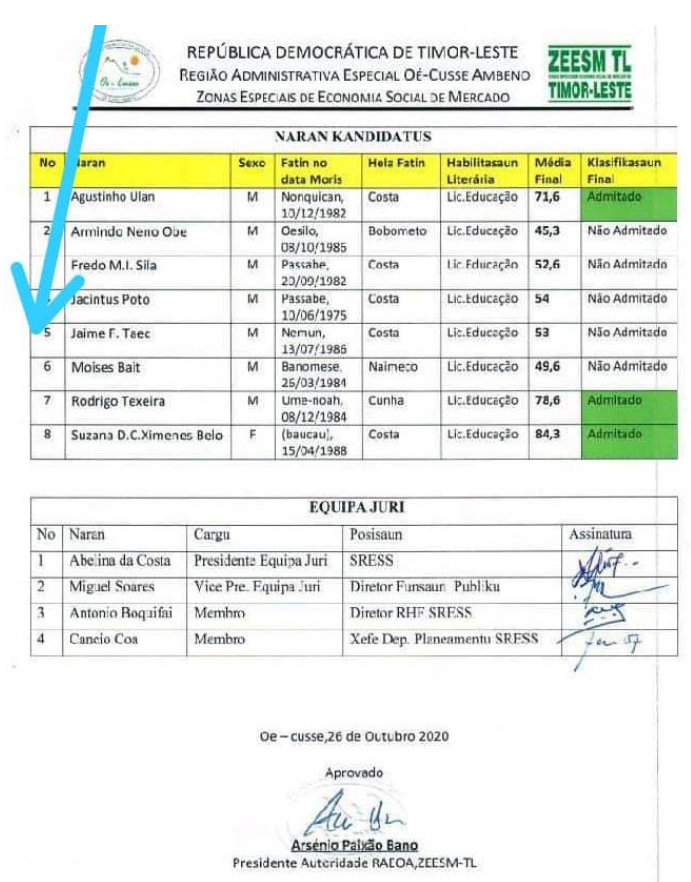

Sumber: Sekretariat Pendidikan Pemerintah Daerah Administratif Khusus Oekusi Ambeno

Kebutuhan pegawai yang direncanakan diawal tidak terpenuhi sehingga pengangkatan calon pengawai negeri sipil (calon inspektur/pengawas sekolah) dan pengangkatan pegawai negeri sipil sebagai inspektur atau pengawas sekolah tidak dapat dilakukan.

\section{SIMPULAN}

Saat ini Pemerintah Daerah Administratif Khusus Oekusi Ambeno belum ditemukan formulasi kebijakan yang tepat untuk secara efektif merekrut calon-calon pegawai negeri sipil yang berkualifikasi tinggi dan memiliki integritas. Pendekatan rekrutmen yang masih tradisional dan sarat dengan campur tangan pejabat terbukti hanya mampu menjaring para pegawai yang bermental korup dan berkinerja rendah. Desentralisasi perekrutan pegawai negeri sipil juga belum efektif untuk mendapatkan calon-calon yang kompeten. Yang terjadi justru lonjakan jumlah pegawai negeri sipil yang tidak didukung dengan kemampuan finansial daerah. Dalam hal ini, Lembaga Pegawai Negeri Pemerintah Timor Leste belum merumuskan payung hukum yang jelas sehingga menimbulkan celah adanya proses rekrutmen yang tidak efektif. Menurut Cayer dan Parkes, (2001) dalam Slamet Rosyadi (2011) dikatakan bahwa kualitas birokrasi pemerintahan bergantung sebagian besar pada kemampuannya untuk merekrut, menyeleksi dan menggaji para pegawai yang memenuhi kualifikasi. Namun, implementasi atas praktik tersebut menemui sejumlah kesulitan. Rosyadi (2011) mengatakan bahwa implementasi penjaringan pegawai negeri sipil daerah ternyata banyak mengalami masalah. Sudah bukan rahasia, proses rekruitmen di daerah diwarnai praktik kecurangan. Banyak daerah yang tidak mematuhi ketentuan dan kuota yang telah ditetapkan. Menurut Rosyadi pengalaman praktik desentralisasi yang tidak efektif dalam melakukan rekruitmen dan seleksi pegawai negeri sipil, maka sebaiknya sistem rekruitmen tidak lagi dilakukan di tingkat lokal dengan hanya mengandalkan pemerintah daerah sebagai aktor dominan. Namun demikian, partisipasi masyarakat pun tidak otomatis akan menghasilkan hasil seleksi yang sehat dan kompetitif. 


\section{DAFTAR PUSTAKA}

Agus. (2018). Penerapan Konsep Good Governance Dalam Rekrutmen dan Pengembangan PNS Di Pemerintah Daerah Kabupaten Lombok tengah. Politea: Jurnal Politik Islam. Vol. 1 No. 2 (Jul-Des).

Edi, S. (2007). Manajemen Sumber Daya Manusia. Jakarta: Kencana.

Etzioni, A. (1982). Organisasi-Organisasi Modern. Alih bahasa oleh Suryatim. Jakarta: Diterbitkan atas kerja sama Universitas Indonesia dan Pustaka Bradjaguna.

Gibson. (2002). Organisasi Perilaku-Struktur-Proses. Terjemahan, Edisi V. Jakarta: Penerbit Erlangga.

Gomes, F.C. (2003). Manajemen Sumber Daya Manusia. Yogyakarta: ANDI.

Herawati, N.R. (2015). Evaluasi Penerimaan Calon Pegawai Negeri Sipil Daerah (CPNSD), Pemerintah Provinsi Jawa Tengah Tahun 2013: Jurnal Ilmu Sosial, Vol. 14. No.1.

Khotimah, K. (2013). Evaluasi Pola Rekrutmen Pegawai Negeri Kabupaten Kudus Tahun 2020: Jurnal Ilmu Pemerintahan.

Martin, J. (2015). Studi Tentang Proses Rekrutmen Pegawai Negeri Sipil Kota Samarinda: eJournal Ilmu Pemerintahan, 3 (4).

Nawawi, H, (2005), Manajemen Strategik, Yogyakarta: Gajah Mada University Press.

Peraturan Pemerintah Nomor 98 Tahun 2000 tentang Pengadaan Pegawai Negeri.

Rachmawanto, A. (2013). Sistem Rekrutmen Pegawai Berbasis Kompetensi: Analisis Perspektif Pengangkatan PPT Menjadi CPNS. Jurnal Kebijakan dan Manajemen PNS: VOL. 7, No.2.

Rakhmawanto, A. (2013). Model Pengangkatan dan Pengembangan Jabatan Pimpinan Tinggi dalam Rancangan Undang-Undang Aparatur Sipil Negara. Pusat Pengkajian dan Penelitian Kepegawaian. Jakarta: Badan Kepegawai Negara.

Rivai, V. (2004), Manajemen Sumber Daya Manusia Untuk Perusahaan. Cetakan Kedua. Jakarta, Raja Grafindo.

Rosento. (2018). Efektivitas Rekrutmen Dalam Kinerja Karyawan Pada Bagian Pemasaran Di CV Ikra Cendana Lintang Jakarta: Cakrawala, Vol. XVIII, No 1.

Rosyadi, S. (2011). Analisis Belanja Daerah Pasca UU No. 32 Tahun 2004 dan Beberapa Dampaknya terhadap Kinerja Pembangunan Daerah. Makalah Simposium Nasional 1 th Ilmuwan Administrasi Negara Indonesia, Universitas Negeri Yogyakarta.

Schuler, R.S., dan Jackson, S.E., (1997). Manajemen Sumber Daya Manusia, (Menghadapi Abad Ke-21), Jakarta: PT. Gelora Aksara Pratama.

Septhinna, E., (2009), Proses Rekrutmen Sumber Daya Aparatur Dinas Pendidikan (Studi Kasus Badan Kepegawaian Daerah Kota Malang): Jurnal Administrasi Publik (JAP), Vol 2, No.1,

Siagian, S.P., (1994), Organisasi, Kepemimpinan, Perilaku Administrasi, CV. Haji Mas Agung, Jakarta.

Simamora, H. (2004). Manajemen Sumber Daya Manusia. Jakarta: Bumi Aksara.

Steers, R. (2005). Efektivitas Organisasi. Jakarta: Erlangga.

Suhendra, D. (2017). Rekrutmen dan Pengangkatan Pegawai Pemerintah Dengan Perjanjian Kerja (PPPK) Menurut Undang-Undang Nomor 5 Tahun 2014. Jurnal Muqqodimah, Volume 1, Nomor 2.

Sulistiyani, A.T., (2003). Manajemen Sumber Daya Manusia, Yogyakarta: Graha Ilmu.

Sulistiyani, A.T., (2004). Kemitraan dan Modul-modul Pemberdayaan. Yogyakarta: Gava Media.

Triandini, F. (2017). Pelaksanaan Rekrutmen Calon Pegawai Negeri Sipil Di Lingkungan Kota Pekanbaru Dengan Sistem Computer Assisted Test (CAT) Pada Tahun 2014: Jom FISIP VOLUME 4 NO 2. 